\title{
Artikel
}

\section{Erfrecht in de onderwereld (deel 2)}

\author{
Mr. L.A.G.M. van der Geld*
}

\section{Inleiding}

De recente liquidaties maken de vraag actueel naar de gevolgen van het verkrijgen van een nalatenschap waarvan de goederen geheel of gedeeltelijk een relatie met een misdrijf of fraude hebben. In het eerste deel ${ }^{1}$ werden de voor het erfrecht relevante bepalingen uit het strafrecht verkend. In dit deel 2 wordt onder meer ingegaan op socialezekerheidsfraude, economische delicten en de navordering van de fiscus. In deel 3 komen de gevolgen van 'criminele' elementen in de nalatenschap voor de afwikkeling en vereffening aan de orde.

\section{Socialezekerheidsfraude}

Onder socialezekerheidsfraude wordt in de Aanwijzing ${ }^{2}$ verstaan 'het verstrekken van onjuiste en/of onvolledige gegevens, dan wel het verzwijgen of niet (tijdig) verstrekken van, voor de bepaling van het recht op uitkering en de duur en hoogte van de uitkering relevante gegevens, met als gevolg dat een uitkering geheel of ten dele ten onrechte wordt verstrekt'. Als er vermoedens zijn dat er voor meer dan $€ 50.000$ is gefraudeerd, worden strafvorderlijke bevoegdheden angewend. Hiervoor geldt echter het principe van artikel 75 van het Wetboek van Strafrecht $(\mathrm{Sr})$, dat overleden personen

Mr. L.A.G.M. van der Geld is juridisch directeur Netwerk Notarissen, kandidaat-notaris en docent aan het Centrum voor Notarieel Recht van de Radboud Universiteit Nijmegen.

1. L.A.G.M. van der Geld, Erfrecht in de onderwereld (deel 1), Tijdschrift Erfrecht 2015, afl. 2, p. 28-31.

2. Aanwijzing sociale zekerheidsfraude (2012A022), gepubliceerd in Stcrt. 2012, 26827. niet strafrechtelijk worden vervolgd. Hierna ga ik verder in op bijstandsfraude die van de nalatenschap/erfgenamen kan worden teruggevorderd.

Op grond van artikel $62 \mathrm{f}$ aanhef en onder b sub 1 van de Participatiewet (PW) kan de gemeente onterecht ontvangen bijstand van de nalatenschap terugvorderen. In artikel $62 \mathrm{~g}$ lid $1 \mathrm{PW}$ is geregeld aan wie de gemeente het verhaalsbesluit richt. De tweede zin van lid 1 ziet op de situatie dat verhaal wordt gezocht op de nalatenschap: het verhaalsbesluit wordt dan gericht tot de 'langstlevende echtgenoot of een der erfgenamen die geacht kan worden bij de afwikkeling van de nalatenschap te zijn betrokken'.

In de casus van de uitspraak van de Rechtbank Amsterdam van 30 mei $2013^{3}$ had erflater vanaf de dag dat hij bijstand ontving tot aan de dag van zijn dood inkomsten gehad uit de handel in verdovende middelen (met uitzondering van de korte periode dat hij in detentie verbleef). Omdat erflater door een misdrijf om het leven werd gebracht, terwijl hij voor $€ 1950$ aan contanten op zak had, kwamen de politie en een sociaal rechercheur van de Handhaving afdeling Opsporing van de Dienst Werk en Inkomen (DWI) in actie. In de woning van erflater worden nog meer contanten, cocaïne en bijbehorend verpakkingsmateriaal gevonden. Verder werden in de woning een gouden ketting en twee waardevolle palmkaketoes aangetroffen. Op de gouden ketting en het geld werd beslag gelegd door de DWI. Deze deelde de erfgenamen mee dat de onterechte kosten van de bijstand zouden worden verhaald op de nalatenschap. De erfgenamen stuurden vervolgens een brief aan de DWI, waarin zij meedelen de nalatenschap van erflater te verwerpen. Enige tijd later maakt een notaris op verzoek van de erfgenamen een verklaring van erfrecht waarin staat vermeld dat zij de nalatenschap beneficiair hebben aanvaard. Het college van burgemeester en wethouders

3. Rb. Amsterdam 30 mei 2013, ECLI:NL:RBAMS:2013:CA3738. 
besluit vervolgens op grond van artikel $62 \mathrm{~g}$ lid 1 van de Wet werk en bijstand (WWB) tot verhaal in rechte. De gemeente stelt dat de erfgenamen, ondanks de afgelegde verklaring van beneficiaire aanvaarding, de nalatenschap zuiver hebben aanvaard door hun gedragingen na het overlijden van erflater. Volgens de erfgenamen hebben zij echter slechts beheershandelingen verricht. De rechtbank oordeelt dat de handelingen van de erfgenamen niet slechts kunnen worden aangemerkt als beheershandelingen. Ze hebben namelijk als 'heer en meester' beschikt over de goederen van erflater door de woning te ontruimen, spullen van erflater onder zich te nemen en de scooter van erflater op naam van de moeder van erflater te zetten. Zij hebben zich daarmee, volgens de rechtbank, ondubbelzinnig en zonder voorbehoud als zuiver aanvaard hebbende erfgenamen gedragen. De verklaring van beneficiaire aanvaarding doet daar niet aan af. Omdat de erfgenamen de nalatenschap zuiver hebben aanvaard, is de gemeente bevoegd haar vordering op hen te verhalen. ${ }^{4}$

Op grond van artikel $62 \mathrm{~g}$ PW kunnen colleges zelf bepalen of ze de bijstandsfraude verhalen. Gemeenten hanteren hier verschillend beleid binnen de bevoegdheden die de verschillende wetten (zoals de Algemene wet bestuursrecht, Awb) aan hen geven. Afhankelijk daarvan is er al dan niet een vordering van de gemeente op de nalatenschap en/of de erfgenamen. De gemeente Rijswijk bijvoorbeeld heeft als beleid dat er alleen wordt teruggevorderd als de erflater een 'behoorlijke nalatenschap' nalaat of sprake is van vorderingen waarbij een zekerheid is gesteld: 'De nabestaanden worden niet aansprakelijk gesteld voor de aflossing van de vordering maar profiteren ook niet onterecht van de nalatenschap terwijl er nog een vordering of lening open staat. ${ }^{5}$ In alle andere gevallen wordt afgezien van invordering bij de nalatenschap dan wel de erfgenamen (die niet anderszins op grond van de wet aansprakelijk zijn) omdat '(...) de nalatenschap meestal zo gering is dat daar ternauwernood de begrafeniskosten, laat staan schulden uit voldaan kunnen worden'.

\section{Economische delicten}

In de Wet op de economische delicten (WED) wordt een zeer divers aantal misdrijven en overtredingen van wetten en regelingen, van milieuwetgeving tot het Vuurwerkbesluit, als economisch delict beschouwd. In artikel 1 en 1a WED staat wat als economisch delict wordt beschouwd. Overtreding van een aantal van de verplichtingen die ex Boek 2 van het Burgerlijk Wetboek (BW) op (bestuurders van) rechtspersonen rusten, wordt in de regel als economisch delict beschouwd. Voorbeelden daarvan zijn het niet bijhouden van het aandeelhoudersregister (art. 2:194 BW) en het niet houden van aantekening van de genomen besluiten (art.

4. De grondslag hiervoor lag in art. 62f WWB, thans de PW.

5. Beleidsregels Terugvordering 2015 gemeente Rijswijk, nr. 14.119620, art. 4:3 en toelichting op dit artikel.
2:120 lid 4 BW $) .6$ Ook het niet nakomen van de verplichtingen die voortvloeien uit het Besluit energieprestatie gebouwen kan tot gevolg hebben dat er een economisch delict wordt gepleegd. Het betreft dan een overtreding van artikel 120 lid 2 van de Woningwet. ${ }^{7}$

In de toepassing van de bepalingen van de WED moet onderscheid worden gemaakt in bepalingen ten aanzien van de reeds tijdens leven voor een economisch delict veroordeelde en een erflater die verdacht is/werd van een economisch delict.

\subsection{Reeds veroordeelde erflater}

In artikel $13 \mathrm{WED}$ is geregeld dat de uitvoering van een verbeurdverklaring (verlies van het recht op goederen) ook na het overlijden van een veroordeelde nog kan plaatsvinden. Dit is een afwijking van de in het commune strafrecht vastgelegde regel van artikel $75 \mathrm{Sr}$, waarin is bepaald dat het recht tot uitvoering van straffen en maatregelen vervalt door de dood van de veroordeelde. Uit de parlementaire geschiedenis blijkt dat de afwijking bewust is gemaakt, omdat de verbeurdverklaring haar achtergrond vindt in de mogelijkheid om grote partijen handelswaar weer in het normale economische verkeer te brengen. ${ }^{8}$ Daarom kan een tijdens leven opgelegde bijkomende straf uit de WED alsnog worden voltrokken. Uit de parlementaire geschiedenis valt af te leiden dat de door het delict behaalde voordelen door erflater niet aan diens erfgenamen ten goede moeten komen. Een en ander betekent mijns inziens dat er in de nalatenschap van erflater een schuld zit in de zin van artikel 4:7 lid 1 onder a BW en dat de erfgenamen verplicht zijn tot afgifte van de verbeurdverklaarde goederen.

Overigens gaat het hierbij niet om goederen die tijdens leven al in beslag zijn genomen: deze gaan namelijk van rechtswege in eigendom van de Staat over zodra de uitspraak in kracht van gewijsde gaat. ${ }^{9}$ Uit de parlementaire behandeling van het wetsvoorstel confiscatie crimineel vermogen lijkt te volgen dat er van de voorziening in artikel $13 \mathrm{WED}$, te weten verbeurdverklaring van goederen die nog niet in beslag zijn genomen, tot dan toe nooit gebruik is gemaakt. ${ }^{10}$

De tenuitvoerlegging van de onderbewindstelling van de onderneming van de reeds veroordeelde erflater vervalt door diens dood (art. 13 lid 2 jo. art. 8 onder b WED). Dit geldt niet voor de tenuitvoerlegging van de reparatoire maatregel van artikel 8 onder c WED, deze kan ook na het overlijden nog plaatsvinden (herstel van de onrechtmatige toestand ofwel een reparatio in integrum). Met deze maatregel is een verplichting opgelegd 'tot verrichting van hetgeen wederrechtelijk is nagelaten, tenietdoening van hetgeen wederrechtelijk is verricht en verrichting van prestaties tot het goedmaken van een en ander, alles op kosten van de veroordeelde, voor zover

\footnotetext{
Art. 1 onder 4 jo. art. 2 lid 4 WED.

Deze overtredingen zijn strafbaar op grond van art. 1a onder 2 WED.

MvT, Kamerstukken II 1947/48, 603, 3, p. 17

MvT, Kamerstukken II 1947/48, 603, 3, p. 18-19: het overlijden van de veroordeelde heeft dan geen invloed meer.

10. Kamerstukken II 1993/94, 23704, 3, p. 23-24.
} 
de rechter niet anders bepaalt'. Deze maatregel heeft als grondslag dat onrechtmatige verhoudingen en situaties weer rechtgetrokken moeten worden door of ten laste van degene die voor deze wanverhoudingen aansprakelijk is. De kosten van de verrichting en uitvoering van deze maatregel zijn voor rekening van de veroordeelde. In een zaak waarin sprake was van oplichting via waardecertificaten kreeg de veroordeelde de maatregel opgelegd het inlegbedrag aan de inleggers te betalen. ${ }^{11}$

\subsection{De verdachte erflater}

Als het aannemelijk is dat iemand een economisch delict heeft gepleegd en deze overlijdt voordat in zijn zaak een onherroepelijke uitspraak is gedaan, dan kan de rechter op vordering van het Openbaar Ministerie de verbeurdverklaring van reeds in beslag genomen voorwerpen uitspreken of ten laste van de 'boedel van de overledene' reparatoire maatregelen in de zin van artikel 8 onder c WED (zie hiervoor) opleggen. Dat de wetgever geen onderscheid heeft willen maken tussen een verbeurdverklaring op basis van een veroordeling (art. 13 WED) en een aanstaande verbeurdverklaring blijkt uit artikel 16 WED.

Het Openbaar Ministerie kan de sanctieoplegging van artikel 16 WED vorderen. Het afschrift van de beschikking van de rechter wordt aan het sterfhuis, als juridisch trefpunt van de erfgenamen, betekend. Daarnaast wordt de beschikking in de door de rechter aan te wijzen nieuwsbladen gepubliceerd. In lid 3 is in enige rechtsbescherming voorzien. Iedere belanghebbende kan binnen drie maanden na de openbaarmaking of betekening een bezwaarschrift tegen de beschikking indienen. $\mathrm{Na}$ het indienen van bezwaar neemt de rechter 'een met redenen omklede beslissing' op het bezwaar. Er staat tegen deze beslissing geen rechtsmiddel open voor de belanghebbende(n)/erfgena(a)m(en). De sanctie wordt overigens pas voltrokken zodra de bezwaartermijn voorbij is.

\subsection{Schadevergoeding}

Op grond van artikel 32 WED kunnen de erfgenamen van een gewezen verdachte tegemoetkoming voor schade vorderen, die erflater heeft geleden door mogelijk ten onrechte opgelegde voorlopige maatregelen. De 'geldelijke tegemoetkoming' vermeld in lid 1 van dit artikel kan ook bestaan in een volledige schadevergoeding. ${ }^{12} \mathrm{Er}$ zijn twee gevallen die voor toekenning van schadevergoeding in aanmerking komen. Het geval waarin de zaak is geëindigd zonder oplegging van straf of maatregel en het geval waarin een straf of maatregel is opgelegd, maar die in verhouding tot de uiteindelijk opgelegde sanctie als 'onevenredig hard' moet worden beschouwd. De te vergoeden schade moet werkelijk geleden schade zijn die het gevolg is van de opgelegde voorlopige maatregel.

Als erflater al tijdens leven een vordering ex artikel 32 WED had ingesteld, komt de toekenning van de schadevergoeding de erfgenamen toe (art. 32 lid 3 WED).

\section{Belastingfraude}

Belastingfraude, ook wel belastingontduiking, kan op verschillende manieren en ten aanzien van verschillende belastingen worden gepleegd. Gedacht kan worden aan het verzwijgen van vermogen en inkomsten of het ten onrechte opvoeren van aftrekposten. De Belastingdienst kan daar bestuursrechtelijk of strafrechtelijk tegen optreden. In de Algemene wet inzake rijksbelastingen (AWR) zijn de bestuurlijke boeten geregeld, de verzuim- en vergrijpboeten, die worden opgelegd door de belastinginspecteur. Er wordt geen bestuurlijke boete opgelegd aan een overleden overtreder en als deze tijdens leven is opgelegd, maar op het moment van het overlijden nog niet onherroepelijk is geworden, vervalt deze. ${ }^{13}$ Als sprake is van een fiscaal delict, wordt het fiscale strafrecht door de rechter toegepast. Bij strafrechtelijke vervolging gelden de regels van het commune strafrecht en wordt dus ten aanzien van een overledene geen strafrechtelijke procedure ingesteld; wel is navordering mogelijk (zie hierna). De erfgenamen kunnen zelf een fiscaal delict plegen door bijvoorbeeld het onjuist of onvolledig doen van aangifte (ter zake van de erfbelasting of de overlijdensaangifte voor de inkomstenbelasting, art. 68 en 69 AWR), maar zich ook schuldig maken aan delicten in het commune strafrecht, zoals valsheid in geschrifte en witwassen. ${ }^{14}$

Erfgenamen kunnen met een navorderingsaanslag worden geconfronteerd. Als erflater tijdens leven te weinig belasting heeft betaald, dan kan deze namelijk worden nagevorderd. De navorderingstermijn is vijf jaar, blijkt uit artikel 16 lid 3 AWR. In artikel 48 van de Invorderingswet 1990 (IW 1990) wordt de aansprakelijkheid van de erfgenamen geregeld. Iedere erfgenaam is aansprakelijk tot het beloop van het erfdeel (naar de waarde in het economische verkeer), vermeerderd met het bedrag dat aan hem is gelegateerd. Het gaat bij deze aansprakelijkheid om de navorderings- en naheffingsaanslagen ten name van erflater voor de inkomstenbelasting (art. 48 lid 1 onderdeel a IW 1990). Verder gaat het om bedragen die na het overlijden van de hoofdelijk aansprakelijk gestelde erflater worden vastgesteld op de voet van artikel 49 IW 1990.

In artikel 44 lid $1 \mathrm{AWR}$ is de vertegenwoordiging geregeld in het uitoefenen van de bevoegdheden en in het nakomen van de verplichtingen die de overledene zou hebben gehad 'ware hij in leven gebleven'. De rechtverkrijgenden onder algemene titel kunnen worden vertegenwoordigd door een van hen, de executeur, de door de rechter benoemde vereffenaar van de nalatenschap of de bewindvoerder over de nalatenschap. Ook ieder van deze personen kan tot nakoming van verplichtingen worden gehouden (tweede zin van lid 1). Uit lid 2 volgt

13. Art. 5:42 lid 1 Awb en art. 67i AWR.

14. HR 7 oktober 2008, ECLI:NL:HR:2008:BD2774: ook vermogensbestanddelen waarover men de beschikking heeft doordat belasting is ontdoken, moeten worden aangemerkt als 'afkomstig (...) van enige misdrijf' in de zin van de witwasbepalingen. 
dat 'stukken betreffende belastingaangelegenheden' van erflater gericht kunnen worden aan een van de hiervoor vermelde personen.

In verband met de bestrijding van de Edelweissroute is op 1 januari 2012 een aantal wetswijzigingen ingevoerd. ${ }^{15}$ De navorderingstermijn voor de erfbelasting is voor buitenlands vermogen onbeperkt geworden. Daarnaast zijn erfgenamen verplicht om, zodra zij op de hoogte zijn van nog niet aangegeven vermogensbestanddelen van de erfenis, hiervan melding te maken bij de Belastingdienst (art. 10a AWR). Op grond van artikel 72 van de Successiewet 1956 (SW 1956) is de executeur verplicht aangifte erfbelasting te doen, met als gevolg dat hij op grond van artikel 47 IW 1990 hoofdelijk aansprakelijk is voor de betaling van de erfbelasting.

In 2002 erft een vrouw een buitenlandse bankrekening van haar echtgenoot. Erflater heeft het tegoed op deze bankrekening nooit opgenomen in de aangifte inkomstenbelasting. Bij de aangifte erfbelasting wordt het tegoed niet vermeld. De verkrijging van de vrouw (exclusief het ook door haar verzwegen buitenlandse tegoed van ruim $€ 300.000)$ blijft onder de vrijstelling voor de erfbelasting, zodat er geen aanslag wordt opgelegd door de Belastingdienst. In 2009 maakt de vrouw gebruik van de inkeerregeling (art. 67n AWR) en geeft zij het buitenlandse banktegoed alsnog op. De inspecteur besluit op grond van artikel 16 lid 4 AWR, waarin de verlengde navorderingstermijn van twaalf jaar voor buitenlands vermogen is opgenomen, een navorderingsaanslag voor de erfbelasting op te leggen. De vrouw gaat in beroep tegen deze aanslag omdat de inspecteur de voortvarendheidseis zou hebben overschreden. Het hof oordeelt echter dat de inspecteur, nadat hij van zijn collega van de inkomstenbelasting de relevante gegevens had ontvangen, de navorderingsaanslag met voldoende voortvarendheid heeft opgelegd:

'(...) de Inspecteur [heeft] niet meer tijd (...) genomen dan in redelijkheid noodzakelijk was voor het verkrijgen van relevante inlichtingen en het vervolgens voorbereiden en vaststellen van de navorderingsaanslag. ${ }^{16}$

In Weekblad voor Fiscaal Recht 2012/166 wordt door Van Eijsden de Edelweissroute als volgt toegelicht: 'Een erflater, $\mathrm{X}$, [bezit] een verzwegen buitenlands (bijvoorbeeld Zwitsers) vermogen (...). Hij geeft de door hem benoemde buitenlandse executeur $Y$ informatie over diens verzwegen buitenlandse vermogen doch zijn erfgenamen informeert hij daarover niet. Bij het overlijden vermeldt de executeur niets over het buitenlandse vermogen in de aangifte voor de erfbelasting. Twaalf jaar na het overlijden van $X$ informeert de executeur $Y$ de erfgenamen en verdeelt het buitenlandse vermogen overeenkomstig de wensen van de erflater of overeenkomstig de wet. De - verlengde - navorderingstermijn was (naar het tot 1 januari 2012 geldende recht) verstreken en de fiscus kon mitsdien niet meer navorderen. De erfgenamen hebben derhalve gewit zwart geld ontvangen en lopen geen enkel fiscaal risico.'

16. Hof Den Bosch 30 januari 2015, ECLI:NL:GHSHE:2015:302.

\section{Naam erflater zuiveren}

Ook na de dood van een veroordeelde kan herziening worden gevraagd in de zin van artikel 479 van het Wetboek van Strafvordering (Sv). Artikel 69 en 75 Sr verbinden overigens aan het overlijden van de verdachte of veroordeelde persoon het gevolg van het verval van het recht tot strafvordering en tot tenuitvoerlegging van de opgelegde straf of maatregel (zie ook deel 1 van deze bijdrage $\left.^{17}\right)$. De mogelijkheid herziening te vragen heeft naast deze bepalingen vooral een symbolische waarde, namelijk tot herstelling van 'de veroordeelde in zijn eer'. ${ }^{18}$ De aanvraag tot herziening kan blijkens artikel $479 \mathrm{~Sv}$ worden gedaan door de echtgenoot dan wel geregistreerd partner van erflater, iedere bloedverwant in de rechte lijn of een bloedverwant in de tweede graad in de zijlijn. Ook de procureur-generaal bij de Hoge Raad heeft de bevoegdheid tot het vragen van herziening na overlijden van een veroordeelde. Wat precies moet worden verstaan onder het in lid 3 van het artikel bepaalde 'deze aanvrage strekt alleen tot opheffing van de veroordeeling tegen den overledene uitgesproken' is niet geheel duidelijk, mede gezien de regeling van artikel 457 lid $2 \mathrm{~Sv}$, dat herziening toelaat indien het feit bewezen is verklaard 'zonder dat ter zake eene veroordeeling is gevolgd'. Het Handboek strafzaken ${ }^{19}$ gaat ervan uit dat redelijke wetsuitleg met zich brengt dat na het overlijden van erflater te wiens laste een feit bewezen is verklaard zonder dat een veroordeling is gevolgd, ook herziening kan worden gevraagd.

Als erflater tijdens leven een strafblad ('justitiële documentatie') heeft, dan blijft dat strafblad bestaan. Hoelang het strafblad blijft bestaan, hangt af van het strafbare feit (of feiten) waarvoor erflater werd veroordeeld: de termijnen voor zware misdrijven, lichte misdrijven en overtredingen verschillen. Als sprake is van een zwaar misdrijf, dan wordt dit uiterlijk twintig jaar na het overlijden van erflater van het strafblad verwijderd. ${ }^{20} \mathrm{Bij}$ lichte misdrijven worden de gegevens uiterlijk twaalf jaar na het overlijden verwijderd. ${ }^{21}$ Voor overtredingen geldt dat deze twee jaar na het overlijden worden verwijderd. ${ }^{22}$ Burgers hebben geen recht op inzage in de justitiële gegevens van een andere burger, ook niet na overlijden. Iemand met een strafblad kan wel zijn eigen strafblad inzien, maar ik ga ervan uit dat dit persoonlijke

17. Van der Geld 2015

18. In HR 3 maart 1986, NK 1987/865 vorderden de erfgenamen herziening en opheffing van de veroordeling.

19. P.A.M. Mevis e.a., Handboek strafzaken online, Deventer: Kluwer, 47.5.

20. Art. 4 en 5 Wet justitiële en strafvorderlijke gegevens. Een zwaar misdrijf kan eerder vervallen, namelijk als er dertig jaar zijn verstreken na de einduitspraak of het volledig voldoen van de strafbeschikking. Zedenmisdrijven worden eerst twintig jaar na overlijden verwijderd.

21. Eerdere verwijdering kan plaatshebben als er twintig jaar zijn verstreken na de einduitspraak of het volledig voldoen van de strafbeschikking.

22. Of eerder, na verloop van vijf jaar na de einduitspraak of het volledig betalen van een strafbeschikking dan wel tien jaar na de einduitspraak of na het volledig voldoen van een strafbeschikking indien er een vrijheidsstraf of taakstraf is opgelegd. 
recht bij overlijden vervalt en niet overgaat op de rechtsopvolgers onder algemene titel.

$\mathrm{Na}$ het Costeja-arrest van het Europese Hof van Justitie op 13 mei $2014,{ }^{23}$ waarin het 'recht om vergeten te worden' werd erkend, is de vraag relevant of erfgenamen resultaten uit een zoekmachine die zien op de veroordeling van erflater, kunnen laten verwijderen met een beroep op het 'vergeetrecht'. In 'Het recht om vergeten te worden na overlijden' ${ }^{24}$ vroeg ik me af of erfgenamen met een beroep op het vergeetrecht namens erflater gegevens kunnen laten verwijderen die erflater verwijderd zou willen hebben omdat ze niet meer relevant (verouderd) zijn, dan wel omdat de betreffende gegevens de erfgenamen hinderen erflater te herinneren op de wijze zoals zij dat wensen. Het is niet zeker of erfgenamen namens erflater of vanwege een eigen belang gegevens van erflater kunnen laten verwijderen. Inmiddels zijn er in Nederland twee uitspraken gepubliceerd van strafrechtelijk veroordeelden die een beroep deden op het vergeetrecht. ${ }^{25}$ In beide zaken werd het beroep echter niet gehonoreerd. De voorzieningenrechter te Amsterdam oordeelde dat negatieve publiciteit als gevolg van een ernstig misdrijf in zijn algemeenheid juist blijvend relevante informatie over een persoon is'. Of 'blijvend' ook ziet op na overlijden van die persoon is vooralsnog niet duidelijk. Men zou namelijk kunnen stellen dat die informatie na het overlijden niet meer relevant is.

\section{Tot slot (deel 2)}

Erfgenamen kunnen na het overlijden van erflater worden geconfronteerd met diens levenswandel langs de grenzen van de wet. Als erflater tijdens leven gefraudeerd heeft met de bijstand, kan de gemeente dit terugvorderen van de nalatenschap en/of de erfgenamen. Of en in hoeverre er wordt teruggevorderd, is per gemeente verschillend. Op grond van de WED kunnen goederen van de nalatenschap verbeurd worden verklaard of erfgenamen moeten een reparatoire maatregel uitvoeren. De gevolgen van belastingfraude van erflater werken ook na overlijden door. Als de erfgenamen vermogen dat erflater tijdens leven verzweeg ook na zijn overlijden blijven verzwijgen, kunnen ook zij zich schuldig maken aan belastingfraude. De inspecteur kan een navorderingsaanslag opleggen, maar een bestuurlijke boete (die wel tijdens leven van de belastingplichtige kan worden opgelegd) kan niet meer worden opgelegd.

HvJ EU 13 mei 2014, ECLI:EU:C:2014:317, C-131/12 en art. 17 van het Voorstel voor een Verordening van het Europees Parlement en de Raad betreffende de bescherming van natuurlijke personen in verband met de verwerking van persoonsgegevens en betreffende het vrije verkeer van die gegevens (algemene verordening gegevensbescherming), $\operatorname{COM}(2012) 11$

24. L.A.G.M. van der Geld, Het recht om vergeten te worden na overlijden, Tijdschrift Erfrecht 2014, afl. 3, p. 60-62.

25. Rb. Amsterdam (KG) 18 september 2014, ECLI:NL:RBAMS:2014:6118 en Rb. Noord-Nederland (KG) 1 mei 2015, ECLI:NL:RBNNE:2015:2122.
Hoewel beneficiaire aanvaarding bij bijvoorbeeld bijstandsfraude een voor erfgenamen 'veilige route' kan opleveren, speelt het handelen van erfgenamen na het overlijden ook een rol. Als erfgenamen bijvoorbeeld het handelen van erflater in zijn onderneming dat als economisch delict kwalificeert voortzetten, kunnen ook zij een economisch delict plegen. Dat geldt ook bij het blijven verzwijgen van vermogen: behalve een navorderingsaanslag kunnen erfgenamen mogelijk strafrechtelijke vervolging tegemoetzien. 